\title{
Towards a Typology of Locutionary Strategies: A Case Study of Selected Nigerian Film Discourses
}

\author{
Acheoah John Emike \\ Department of European Languages- Faculty of Arts- Federal University- Nigeria \\ actualemike@gmail.com
}

\begin{abstract}
Language users violate linguistic conventions because meaning is not exhaustive. They control language for effective communication. This study attempts a classification of locutionary (communicative) strategies via an analysis of selected utterances from Nigerian film discourses (recorded conversational exchanges). The analysis presents the contextual nuances that direct each utterance (P-crafting Features). For the elucidation of direct, indirect, literal and nonliteral communicative potentials of illocutionary acts, this study hinges on Bach and Harnish's Speech Act Schemata. For the explanation of the pragmatic nuances that impinge on language use, the study explores Acheoah's Pragma-crafting Theory. The study concludes that locutionary strategies include: using quantifications that do not seem complete; ascribing quality to the object requested; offering to do what $\mathrm{H}$ will not accept; using a constituent to demand a whole; declaring what $\mathrm{H}$ will not do if he possesses a certain quality; and expressing a dissentive on gratitude.
\end{abstract}

Keywords: pragmatics, speech acts, locutionary strategies, Speech Act Schemata, Pragma-crafting Theory

\section{Introduction}

In contemporary research, pragmatic analysis provides incisive investigation of communicative events. This study evolves novel categorization of locutionary strategies that are typical of human communication. The categorization of locutionary strategies presented in this study, gives the readers tips on the selection of linguistic structures for effective communication.

Most contemporary pragmatic theories are neo-Gricean because they explore Gricean postulations in the investigation of a wide range of language phenomena. For example, they acknowledge that there is a fundamental distinction of what a speaker says and what he implicates. In addition, they hold the view that human communication is rational, principle-driven and involves the process of cognition.

This study examines locutionary strategies in selected utterances from Nigerian film discourses with a view to categorizing such strategies. Communication is not effective if speakers and hearers do not share common background information. Perhaps, this view aligns with Searle, cited in Brenders $(1987$, p. 340) who posits that "in the performance of illocutionary act the speaker intends to produce a certain effect by means of getting the hearer to recognize his intention to produce that effect, and furthermore, if he is using words literally, he intends this recognition to be achieved..." Indeed, the typologies evolved in this study reveal how the propositional contents of speech acts try to get the world to match speakers' words as opposed to the words-to-world direction of fit in Searle's theorizing.

\section{Significance of the Study}

The taxonomy of speech acts in the literature is different from the categorization of locutionary strategies. However, the taxonomy of speech acts contained in the literature does not examine the 
categorization of speech acts in terms of the pragma-rhetorical nuances that underpin them around the clause; this study advances knowledge in this regard. It is not enough to classify certain linguistic stretches as informative, assertive, question, and so on as done by the classical scholars of pragmatics. This study therefore explains the linguistic constituents that make speech acts (informatives, assertives, questions, ascriptives, disputatives, assentives, dissentives, declaratives, offers, direcdtives, commissives, responsives, etc.) potent as locutionary strategies in different communication contexts and situations.

\section{Literature Review and Theoretical Underpinnings}

Austin (1962) categorizes speech acts thus: Locutionary act: The utterance of a sentence with determinate sense and reference;

Illocutionary act: The making of a statement, offer, promise, etc. in uttering a sentence by virtue of the conventional 'force' associated with it (or with its explicit performative paraphrase);

Perlocutionary act: The bringing about of effects on the audience by means of uttering the sentence, such effects, being special to the circumstances of utterance.

Speech acts make it possible for language users to do things with words. The actions performed with words are the illocutionary goals or communicative intentions of speakers. They include making statements, asking questions, giving orders, etc. Brenders (1987, p. 331), notes that "speech act theory, as a part of the philosophy of language, has been concerned with analyzing the performance of linguistic acts (asserting, promising, questioning) as a rule-governed form of behaviour." To understand the meaning of speech acts, it is necessary to locate their situational and individualistic articulation in a particular communicative event. Speech acts are crucial to human communication. Propositions and social phenomena are conveyed by them. Labove (1972, p. 297) rightly notes that "no use of language can be divorced from its social context since special meaning is parasitic upon language." Without speech act theory, it will be difficult to explain the principles that underpin the encoding and decoding of utterances. The normative rules of language cannot account for the intentions, attitudes, and other dynamics of human communication.

The literature of pragmatics acknowledges that language use is not arbitrary. It is determined by the functions language is engaged for in spoken and written discourses. This study is anchored by a two-fold theoretical underpinnings: Bach and Harnish (1979) and Acheoah (2015):

\subsection{Bach and Harnish (1979)}

The speech act theory of Bach and Harnish is relevant to this study in terms of its stance that illocutionary acts can be direct, indirect, literal or non-literal. No matter the situational context of a communicative event, different strategies abound for communicating speakers' intentions. This predisposition is inherent in language users. The approach of Bach and Harnish to speech act is intention and inference based. They contend that for speakers to perform illocutionary acts, it is intended that listeners have the understanding of the acts (mutual contextual beliefs). It is their claim that the act of conversation or interactional talk has to involve an inferential process. Their terminology Speech Act Schemata (SAS) refers to an inevitable part of the inferential process in a communicative event. To them, mutual contextual beliefs (MCBS) between a speaker and his hearer facilitate the inferential process, as the inference made or is expected to be made by the hearer does not just depend on what the speaker says but on the contextual knowledge shared commonly by the speaker and hearer in discourse. To infer what $\mathrm{S}$ is saying $\mathrm{H}$ depends also on the Presumption of Literalness (PL). H should know when the linguistic communication of S is "within or without" the bounds of literalness, and if $\mathrm{S}$ is speaking in a non-literal dimension, $\mathrm{H}$ should not only acknowledge it, but should also be able to understand what such speech by $\mathrm{S}$ means; $\mathrm{H}$ should have a mastery of the acts in S's non-literal language. The non-literal language involves the use of indirect speech acts.

Apart from MCBS, Bach and Harnish recognize other types of beliefs (shared by an entire linguistic community) which the hearer relies on for his inferences. These are: 


\section{[1] Linguistic Presumption (LP)}

[2] Communicative Presumption (CP).

Linguistic Presumption (LP) refers to the moral belief that members of a Linguistic Community (LC) share on the particular language (L) in question. Therefore, any expression (e) uttered by a member to any member of the community, is taken by $\mathrm{S}$ (speaker) for granted that is, $\mathrm{S}$ presupposes that the hearer $(\mathrm{H})$ will be able to identify what he is saying. Whenever a member, S, says something in L to another member $\mathrm{H}$, he is doing so with some known illocutionary intent. If $\mathrm{H}$ does not think the (CP) is operative then $\mathrm{H}$ has no grounds to infer any illocutionary intent from $\mathrm{S}$ 's utterance.

In Bach and Harnish's framework, an act is communicatively successful as soon as the hearer recognizes the speaker's illocutionary intention. Therefore, "the intended effect of an act of communication is not just any effect produced by means of recognition of the intention to produce certain effects on (or in) the hearer." To buttress this claim, Bach and Harnish point out that indirectness, for instance, may have a perlocutionary effect such as protecting the hearer's feelings or making him suspicious. Also, they consider perlocutionary effects to be beyond the scope of communication because "there is no limit to what can result from speech acts" (Bach and Harnish, 1979, p. 17). Hence, unlike most earlier scholars, they distinguish between communication and what happens as a result of it. Bach and Harnish recognize several types of strategies in the inferential process:

a. Locutionary Strategy - the hearer's inference from the locutionary act or the utterance per se and what the utterance means in L. This is based on H's knowledge of the language, the LP, the $\mathrm{CP}$ and MCBs.

b. Direct Literal Strategy $-\mathrm{H}$ infers from the PL whether or not $\mathrm{S}$ means what he says and nothing else. This helps $\mathrm{H}$ to identify the act.

c. Literally Based Indirect Strategy - H depends on the MCBs, CP, and the utterance to determine whether, under the circumstance there is some action connected with the literal utterance.

d. Direct Nonliteral Strategy - from the MCBs, CP, and the utterance, H's knowledge of the literal meaning of the utterance, $\mathrm{H}$ infers that $\mathrm{S}$ 's utterance must be non-literal and indirect since another act is connected with the overt one which $\mathrm{H}$ recognizes.

e. Nonliterally Based Indirect Strategy the EP, the utterance, and MCBS lead H to infer that S's utterance must be nonliteral and indirect since another illocutionary act is connected with it. See Bach and Harnish (1979) for an elaborate discussion of SAS and speech act taxonomy.

\subsection{Acheoah (2015)}

Within the framework of the Pragma-crafting Theory, the discrete components that make language mean or easy to mean are revealed. These components (P-crafting Features) can only be noticed and understood via careful study of the locutionary, illocutionary and perlocutionary acts in a communicative event. Contending that effective use and interpretation of language is essentially a "pragmatic" process of "crafting" Acheoah presents a scholarly overview of hitherto-neglected issues in the literature of pragmatics. "Every Pragma-crafting (P-crafting) involves "illocrafting", "uptake" and "sequel". Therefore, P-crafting is a super-ordinate pragmatic act which produces linguistic and extra-linguistic elements of communication. At different stages of a communicative event, there is a candidate for inference. At every such stage, the interactive and non-interactive participants explore P-crafting Features (inference features): indexicals (INDXLs), Shared Macro-knowledge (SMK), Shared Contextual Knowledge (SCK), Shared Knowledge of Emergent Context (SKEC), Geoimplicatures (GIs), Linguistic Implicatures (LIs), Behavioural Implicatures (BIs), Contextual Presuppositions (CPs), Pragmadeviants (PDs), Object Referred (OR) and Operative Language (OL) to ascertain messages and sequels (Acheoah, 2015, p. 21-32)." Notions in the theory include: 
[1] P-crafting: This is a super-ordinate notion which has dual components: Event and Text; these two components unfold as discrete multiple categories in the explanation of how communication is interpreted from speaker-hearer or writer-reader ends.

[2] Event: It concerns participants of discourse who are either interactive or non-interactive. The interactive participants perform any or all of these acts to the discourse: linguistic, extralinguistic and psychological acts. On the other hand, the Non-interactive Participants are those who are present in the setting, but do not perform any act in the discourse. Even when they perform linguistic, extra-linguistic or psychological acts, such acts are not connected to the discourse in progress.

[3] Text: Components of Text are Setting, Theme and P-crafting Features. The dynamics of communication are captured by P-crafting Features which have discrete theoretical notions demonstrated by the Interactive Participants in three different frames: linguistic acts, extralinguistic acts and psychological acts.

[4] Interactive participant: This is an interlocutory participant. He makes linguistic, extra-linguistic and psychological contributions that do not only impinge on the interpretive process in discourse, but also determine or generate sequel.

[5] Non-interactive Participant: A participant is categorized as non-interactive when he does not function in an on-going communicative event, although he is intentionally or accidentally present in the physical context.

[6] Setting: This is the physical context of the communicative event (Text) in both remote and immediate sense.

[7] Theme: This category is the message conveyed in/by Text. Text may convey one or more themes that can only be identified when communicative acts (acts performed by Interactive Participants) interact with communicative features (P-crafting Features).

[8] P-crafting Features: These elements are instrumental to understanding the interlocutory roles of the Interactive Participants. The elements include: Inference, Indexical Shared Macroknowledge, Shared Contextual Knowledge, Shared Knowledge of Emergent Context, Geoimplicatures etc.

Inference has to do with making logical deductions from available linguistic and extralinguistic data. Indexicals are grammatical categories that have the potential to establish the relationship between language and context. Shared Contextual Knowledge is the available pieces of information which only participants of the on-going discourse have for the communication to thrive. When discourse has an Emergent Context, perlocutionary effects may not occur (effects intended by speakers), despite the appropriateness of participants and circumstances. Any situation that suddenly emerges in an on-going discourse is emergent. An Emergent Context becomes Shared Knowledge of Emergent Context when it translates to common knowledge to the participants of discourse. It is vital in terms of its potential to determine illocutionary forces and relocate sequel. It is a candidate for inferences. Linguistic implicatures are meanings implied through language while Behavioural implicatures are meanings implied through extra-linguistic and psychological acts. Contextual Presuppositions are products of Shared Contextual Knowledge; in a specific discourse, participants deduce meanings from verbal and non-verbal data limited to them. The meanings deduced are treated as Background Assumptions (BAs) which direct interlocutory roles. DCs (Decoders) imply that ENCs (Encoders) know that certain VEs (Verbal Elements) and NVEs (Non-verbal Elements) are deduced as OR (Object Referred) in OL (Operative Language).

[9] Linguistic Acts: There are five components in this category:

1. Speech acts (direct, indirect and pragmadeviant);

Pragmadeviants are deviant forms of expressions which participants use as part of illocutionary strategy or creative indulgence. See Acheoah (2015) for an elaborate discussion of the theory. 


\section{Methodology}

The data of this study are instances of language use in the films: sixteen utterances are analyzed in terms of locutionary act, illocutionary act and p-crafting features (pragmatic nuances). Each utterance is first labeled as a definite locutionary strategy before it is explained.

\section{Data Analysis}

For the purpose of this study, a brief analysis of each utterance is satisfactory:

\section{Strategy One: Using quantifications that do not seem complete}

Locutionary Act: He arrived at 2:11 p.m.

Illocutionary Act: to make $\mathrm{H}$ believe that the proposition is true

Pragma-crafting Features: The force of the utterance is targeted at the time of the arrival. On hearing the utterance (locutionary act), the hearer (henceforth $\mathrm{H}$ ) has no reason to think that the additional 1 (one) minute (10 minutes plus 1 minute) is not sincere; the addition implies that the speaker (henceforth $S$ ) carefully monitored the time of the arrival, thus the expected perlocutionary (believing $\mathrm{S}$ ) is achieved. Other examples of strategy one are:
a. Ade is 9 years old ${ }^{1}$;
b. Adamu lived there for 12 years and two weeks ${ }^{2}$.
c. She scored $91 \%$ in Mathematics examination ${ }^{3}$.

The above strategy can also be used in the following ways:

d. to request more than what is stated e.g.:

Give me 499 kobo (requesting 500 kobo from $H$ who does not see any need to look for change);

e. to make $\mathrm{H}$ believe the mentioned quantity e.g.:

The project cost the government nine million, five hundred and forty six thousand, two hundred and sixty nine kobo.

f. to make a commodity/service seem cheaper e.g.:

Pay me six thousand, nine hundred and ninety nine naira for the product.

\section{Strategy Two: Ascribing quality to the object requested}

Locutionary Act: Even little money settles disputes.

Illocutionary Act: to request money from $\mathrm{H}$

Pragma-crafting Features: The utterance was uttered in a context that conveys its meaning. S requested bribe via topic shift. $\mathrm{S}$ (a policeman at a checking point) discovered that $\mathrm{H}$ is guilty of violating a traffic regulation. One expected the policeman to take an action against this offender according to the laws of the country. Surprisingly, $\mathrm{H}$ received an inappropriate treatment. The word little in the utterance is a quality ascribed to money to motivate $\mathrm{H}$ to comply. Considering the idea that a little amount of money was requested, $\mathrm{H}$ was not willing to plead; he thought was a waste of time to do so. Generally, when people are aware that there will be a very light consequence for wrong doing (shared knowledge), they keep committing such crimes. In the Operative Language (English) Even is not commonly used to begin a conversation the way this policeman did. Therefore, its usage in the utterance is comic, and prevented the situation from being tense. The strategy also encouraged $\mathrm{H}$ to comply. In some instances, $\mathrm{S}$ uses a different object rather than a mere adjective, to ascribe quality to an object requested. For example, to request monetary bribe, a policemen may say to a taxi-driver:

g. Kolanuts are not rejected by the gods. 
William P. Alston, cited in Savas (1994, p. 48) submits that "though an individual cannot determine which illocutionary rules are attached to a sentence, $\mathrm{S}$, in the language, she can determine whether a particular utterance of $\mathrm{S}$ is within the range of activity in which a certain illocutionary rule applies, for it depends on U's intentions whether she is practicing pronunciation, testing a microphone or talking straightforward literal use of S. This makes it clear how it can be understood... what illocutionary act potential if any, is being exploited."

\section{Strategy Three: Using a constituent to demand a whole}

Locutionary Act: You are the Guest Speaker for the Conference.

Illocutionary Act: inducing $\mathrm{H}$ to attend the conference

Pragma-crafting Features: The encoder was told that the decoder had a history of not fulfilling promises. The utterance was able to prevent the attitude because $\mathrm{H}$ viewed the offer as a rare privilege. Indeed, $\mathrm{H}$ might start preparing his speech soon after the declaration. If he prepared the speech, that gets him more committed to the conference (Behavioural implicature).

\section{Strategy Four: Offering to do what $\mathrm{H}$ will not accept}

Locutionary Act: Let me get to the back seat.

Illocutionary Act: inducing $\mathrm{H}$ to go to the back seat

Pragma-crafting Features: The participants were in a taxi. One passenger reached his destination and came out. The encoder of this utterance was not comfortable where he sat (the front seat) with another passenger, and desired to relocate to the space provided by the passenger who came out of the back seat (Shared Knowledge of Emergent Context). S thought it would not be polite to request $\mathrm{H}$ to go to the back seat for his (S's) convenience (world knowledge about courtesy), and so, offered to be the one to do so. But $\mathrm{S}$ was sure that $\mathrm{H}$ would decide to rather be the one to go to the back seat because while $\mathrm{S}$ sat between the driver and $\mathrm{H}, \mathrm{H}$ sat close to the right front-door (Contextual Presupposition).

There is a systematic relationship between expressions and what they refer to in the world. Because discourse situations or contexts are dynamic, the participants have to use language skillfully. Words, phrases or sentences have to be carefully selected, put together and then used for effective communication. What speakers intend to communicate is paramount as far as pragmatic use of language is concerned. This does not imply that there are no instances of communicating unintended messages. The patterning of linguistic units corroborates the claim that linguistic facts explain the functional dimensions of language in context.

\section{Strategy Five: Using a constituent to imply a condition}

Locutionary Act: We thank God that we are not picking papers on the streets.

Illocutionary Act: declaring to be in a state of good mental health/declaring to be sane; thanking God for being in a state of good mental health/thanking God for being mentally sane

Pragma-crafting Features: The utterance was from a Pastor who was delivering a sermon to his congregation. Via his knowledge (Shared Macro Knowledge) that only mad people pick papers from one street to another (Behavioural Implicature), the encoder conveyed a clear message. The implied linguistic act (madness) and non-linguistic act (picking papers on the streets) are co-referential. The speaker's choice of the non-linguistic act was aimed at achieving psychological act - evoking in the audience, a great feeling of gratitude to God. This is a potent communicative strategy. A perlocutionary act is therefore not conventionally achieved just by uttering that particular utterance, and includes all those effects intended or unintended often indeterminate, that some particular utterance in a particular situation may cause. 


\section{Strategy Six: Declaring what $\mathrm{H}$ will not do if he possesses a certain quality}

Locutionary Act: A responsible father will not abandon his family.

Illocutionary Act: requesting $\mathrm{H}$ to desist from an action/attitude

Pragma-crafting Features: $\mathrm{H}$ interpreted the utterance using Contextual Presupposition. If there were Shared Knowledge of Emergent Context ( $S$ 's sudden knowledge of an incident in which $\mathrm{H}$ abandoned his family), then this utterance would imply that $\mathrm{H}$ is irresponsible. But at the same time, the utterance requested $\mathrm{H}$ not to abandon his family. Without Contextual Presupposition or Shared Knowledge of Emergent Context, the utterance is simply an existential request. As expected, speakers' illocutionary strategies will always be determined by their communicative intentions(s). It is instructive that the desire to be polite as a result of sociolinguistic variables such as the age of one's interlocutor, can inform the use of Strategy Six in discourse.

\section{Strategy Seven: Mentioning a constitutive referent}

Locutionary Act: Omoba is in Ise Shrine.

Illocutionary Act: to inform $\mathrm{H}$ that they had arrived in Etsako, Edo State

Pragma-crafting Features: $\mathrm{S}$ used the utterance to inform $\mathrm{H}$ that Omoba was already in Ekwotso when $\mathrm{H}$ requested to know where Omoba had reached in the on-going journey. Omoba could not be in Ise Shrine without having arrived in Ekwotso (shared knowledge among the interlocutors). A speaker makes choices in language use because inference-making is part of his/her interlocutor's task. Apart from facilitating the use of polite predications, locutionary strategies facilitate the use of short, straightforward predications which may be very useful in certain circumstances. Psychological contexts for example, may necessitate the use of short predications so long as such predications are easy to mean. It is possible for the constitutive referent to be an activity/event rather than a place or object. For example, to mean I am in Kebbi State - the only place where the Argungu festival takes place in Nigeria, $\mathrm{S}$ may say to $\mathrm{H}$ :

h.) I am in Argungu Fishing Festival.

\section{Strategy Eight: Making an ironical remark}

Locutionary Act: The footballer is so skillful that he could not score even a single goal throughout the tournament.

Illocutionary Act: rejecting the claim that the footballer is skillful

Pragma-crafting Features: The Linguistic Presupposition in the use of skillful was the basis for $\mathrm{H}$ to infer that the utterance is a sarcastic remark. In the utterance, Tournament presupposes that the socalled skillful footballer was involved in more than one match. The fact that a skillful footballer may not even score a single goal throughout a tournament does not make this locutionary strategy unworthy of scholarly attention. There are other examples of sentences that capture the indirect communicative potential of Strategy Eight.

\section{Strategy Nine: Expressing gratitude to $\mathrm{H}$ for performing an action}

Locutionary Act: Thank you for attending the seminar.

Illocutionary Act: requesting $\mathrm{H}$ to make remarks on S's delivery at the seminar; thanking $\mathrm{H}$ for attending the seminar

Pragma-crafting Features: S presented a paper at a seminar and is so sure that he did well. He desires praise from $\mathrm{H}$ and so uses the utterance as a conversational opening gambit. Remarks made by $\mathrm{H}$ about S's ability/performance can be taken by $\mathrm{S}$ as the views of those who attended the seminar. This illocutionary strategy can also be used as a requestive speech act to induce $\mathrm{H}$ to take certain action(s) in future. For example, the utterance below can make $\mathrm{H}$ indulge in more acts of generosity towards his interlocutor: 
i.) I told my Pastor to pray for you because of the financial assistance you rendered to my family.

\section{Strategy Ten: Making an accusative remark}

Locutionary Act: You did not reply my congratulatory text message.

Illocutionary Act: convincing $\mathrm{H}$ that a congratulatory text message was indeed sent

Pragma-crafting Features: S knew it is conventional (Shared Macro Knowledge) for her to send a congratulatory message to $\mathrm{H}$ after receiving the news of $\mathrm{H}$ 's promotion at her place of work. Although S had planned to do so earlier, she could not before meeting $\mathrm{H}$ at a supermarket. The only way to avoid feeling of guilt was to strongly convince $H$ that the text message was actually sent; hence, $\mathrm{S}$ uses Strategy Ten which even made H apologize; thus, locutionary strategies can relocate perlocutionary sequel. A mobile-phone text message may not be noticed immediately it was sent. Considering the fact that there are conventional principles that underpin the articulation of locutionary acts in discourse, it is logical to conclude that indeed, pragmatics is inevitably linked with syntax and semantics ${ }^{1}$.

\section{Strategy Eleven: Making a predication about the source of an action.}

\section{Locutionary Act: Up NEPA!}

Illocutionary Act: informing $\mathrm{H}$ that NEPA has restored electricity; praising NEPA for restoring electricity

Pragma-crafting Features: The participants are aware of what the acronym NEPA means (Geoimplcature) in that speech community. There are instances in which speakers use Strategy Eleven to inform their interlocutors that NEPA (National Electric Power Authority) has taken away electricity. In such instances, $\mathrm{S}$ is joking or deceiving $\mathrm{H}$ (illocutionary act). Language use is effective if inferences can easily be made by its decoder. Decoding utterances involves the making of inferences that are either assumptions or uttered expressions. When utterances are uttered, the hearers have to reasonably establish the rationale for working out the meanings.

\section{Strategy Twelve: Using an abrupt entailment}

Locutionary Act: We have eaten a lot of fresh fish.

Illocutionary Act: informing $\mathrm{H}$ that the fresh fish he sent through his wife was received

Pragma-crafting Features: $\mathrm{S}$ gives $\mathrm{H}$ a phone call using the utterance as an opening gambit. The utterance is abrupt because it is not the usual way of beginning a telephone conversation. However, $\mathrm{S}$ uses it to convey a direct message (informative) and an indirect message (expressing gratitude to $\mathrm{H}$ for purchasing a lot of fresh fish for him). The entailment is clear: if the fresh fish were not so much, the encoder would not have said a lot of it was eaten. As soon as $\mathrm{H}$ hears the utterance, one expects any of the responsive speech acts below, to establish the fact that $\mathrm{H}$ inferred the utterance correctly:
j.) Don't mention;
k.) What are friends for?
1.) We thank God.
m.) You are welcome.

\section{Strategy Thirteen: Making a normative predication}

LocutionaryAct: Tomorrow is Sunday.

Illocutionary Act: informing $H$ that he $(S)$ will not be in shop the next day

Pragma-crafting Features: $\mathrm{S}$ requests to know if $\mathrm{H}$ will be in shop the next day. Strategy Thirteen (H's response) is normative; as a norm, Christians worship in church on Sundays. Hinging on this Shared Macro Knowledge, S inferred H's messages which are as follows:

n.) I will be in church tomorrow;

o.) I will not be in shop tomorrow; 
p.) The reason why I will not be in shop tomorrow is that I will be in church.

\section{Strategy Fourteen: Expressing a dissentive on gratitude}

Locutionary Act: Abah! What is fifty thousand naira?

Illocutionary Act: informing S that it was actually a gift of fifty thousand naira that was sent to him Pragma-crafting Features: H doubts whether it was the exact amount of money (fifty thousand naira) which she sent to her uncle, through a friend, that was actually given to this uncle. Strategy Fourteen is a way of stating the amount of money without an implicature that questions the integrity of the friend who delivered the money.

\section{Strategy Fifteen: Claiming to have forgotten the time of an achievement}

Locutionary Act: I cannot remember when I obtained my First Degree.

Illocutionary Act: seeking honour from $\mathrm{H}$; ridiculing $\mathrm{H}$

Pragma-crafting Features: Although S had his First Degree just the year before this conversation, he used the utterance not only to humiliate $\mathrm{H}$ who had been boasting about being a First Degree holder, but also to get respect from $\mathrm{H}$. The sentence below uttered by a football Coach will also suffice as Strategy Fifteen:

q.) I cannot remember when last my team lost a football match.

John T. Kearns, cited in Savas (1994, p. 51) asserts that "a linguistic act is a meaningful intentional act. The words used to perform linguistic acts are not meaningful. But words are conventionally associated with certain types of acts and will normally be used to perform those kinds of acts. The meaning of someone's linguistic act is her intention for the act. Most words are conventionally associated with more than one type of act. The language user's intention determines which particular type of act she performs. And it is common, by a slip of the tongue or carelessness, for a speaker to use the wrong word in performing a linguistic act. She still performs the kind of act she intends, but the expression she uses will probably mislead her audience."

\section{Strategy Sixteen: Generalizing the time of an action}

\section{Locutionary Act: I obtained PhD less than fifteen years ago.}

Illocutionary Act: seeking praise/regard from $\mathrm{H}$

Pragma-crafting Features: Strategy Fifteen and Strategy Sixteen are subtle, egocentric predicates. In the latter, $\mathrm{S}$ intentionally tasked H's reasoning towards achieving a psychological act. There is no reason for $\mathrm{H}$ to think that $\mathrm{S}$ obtained the $\mathrm{PhD}$ just three years before the conversation; $\mathrm{I}$ hold this view because three years ago is not approximately fifteen years ago. The sentence below is also a good example of Strategy Sixteen:

r.) I fasted for less than seventy days.

\section{Discussion and Conclusion}

The background assumption of any communication event (shared knowledge) is essentially the presupposition(s) about the context. According to Savas (1994, p. 1), "the study of illocutionary act should be acknowledged as an indispensable component of the study of meaning." If one knows the illocutionary act performed in an utterance, one will definitely understand the speaker's communicative intention. However, speaker-meaning and sentence-meaning (normative meaning) may be different. The literature is replete with contentious positions on the nature of speech acts partly because of the complexity of illocutionary acts. Scholars agree that illocutionary acts have roles to play in the understanding of standard speaker-meanings and occasional speaker-meanings. More research in semantics can resolve conflicting views on the intractable nature of speech acts. Given that speech acts are basically intentional acts, such additional research is timely. The intentional nature of illocutionary acts is captured by David Harrah, cited in Savas (1994, p. 375) 
who notes that "most speech acts seem to be focused and directed. They are intended as coming from the agent and going to the receivers or audience. They are intended to have a certain point, and they are intended to be construed as having a certain point." Faigenbaum (2003, p. 92-93) posits that "the meaning of the sentence is its use in the speech act... speaker meaning is a matter of the intentional content." Thus, mastery of speech acts in terms of typology (linguistic competence) is instrumental in pragmatic use of locutionary acts (communicative competence) in discourse.

This study proposes that locutionary strategies include: mentioning a constitutive referent; using quantifications that do not seem complete; generalizing the time of an action; ascribing quality to the object requested; offering to do what $\mathrm{H}$ will not accept; expressing a dissentive on gratitude; using a constituent to demand a whole; and declaring what $\mathrm{H}$ will not do if he possesses a certain quality. Despite the various types of locutionary strategies presented in this study, two facts remain clear: language use is not incidental; locutionary strategies not exhaustive. Indeed therefore, the goals of pragmatics is to process language for smooth communication. Adequate sentential examples (a-r) are presented in this study to depict pragmatic language use as a creative indulgence.

\section{Notes:}

[1] In $\mathrm{a}, \mathrm{b}$ and $\mathrm{c}$, illocutionary force is achieved via the underlined units because they are doubtreducing.

[2] For example, a sarcastic adverbial element may end the sentence: The politician is honest indeed! When $\mathrm{S}$ processes the utterance, it becomes clear to $\mathrm{H}$ that it is uttered with disgust. In a situation in which a mother does not wash her hands after cleaning up her baby's 'mess', her husband can simply say: What a hygienic practice! The psychological acts which speakers intend to perform on hearers, direct locutionary strategies. Whereas You are not hygienic is plainly insulting, What a hygienic practice is not; in uttering the latter, $\mathrm{S}$ amuses $\mathrm{H}$, but communicates a thought-provoking message.

[3] As revealed in the film, the encoder actually fasted for 13 days.

\section{References:}

[1] Acheoah, J. E, The Pragma-crafting Theory: A Proposed Theoretical Framework for Pragmatic Analysis. American Research Journal of English and Literature, 1(2)(2015), 21-32, https://doi.org/10.21694/2378-9026.15019

[2] Austin, J., How to Do Things with Words. Cambridge: Harvard University Press,(1962), https://doi.org/10.1093/acprof:oso/9780198245537.001.0001

[3] David A. B., Fallacies in the Coordinated Management of Meaning: A Philosophy of Language Critique of the Heirachical Organaization of Coherent Conversation and Related Theory. Quarterly Journal of Speech 73(3)(1987),329-348, https://doi.org/10.1080/00335638709383812

[4] Faigenbaum, G.,Conversation with John Searle. Montevideo: Libros En Red,(2003).

[5] Labov, W., The Study of Language in Its Social Context. In Pier Paolo Giglioli (Ed.) 283-307. Harmondsworth: Penguin,(1972).

[6] Savas, L. T., Foundations of Speech Act Theory, London: Routledge,(1994).

[7] Searle, J., Speech Acts: An Essay in the Philosophy of Language. New York: Cambridge University Press,(1969). 